\title{
Comparative Identification of Wellhead Protection Areas for Municipal Supply Wells in Gaza
}

\author{
Yunes Mogheir ${ }^{1}$, Gorge Tarazi ${ }^{2}$ \\ ${ }^{1}$ Environmental Engineering Department, Engineering Faculty, Islamic University of Gaza, Gaza, Palestine \\ ${ }^{2}$ Civil Engineering Department, Engineering Faculty, Islamic University of Gaza, Gaza, Palestine \\ E-mail:ymogheir@iugaza.edu.ps \\ Received August 25, 2009; revised September 2, 2009; accepted December 28, 2009
}

\begin{abstract}
Groundwater is the only source of fresh water in Gaza Strip while its inhabitants and its water consumption increased rapidly. This study aims at preserving and protecting the groundwater from any pollutants caused by 141 industrial installations through the work of delineation of Wellhead Protection Areas (WHPA) for 47 Municipal Supply Wells in Gaza Governorate boundaries. WHPA has been determined in three different methods: Calculated Fixed-Radius Method (CFR), Analytical Method (AM), and Wellhead Analytic Element Model (WhAEM2000) which is currently used by the United States Environmental Protection Agency (EPA). These methods mainly depend on the time it takes groundwater to travel a specified horizontal distance. Three well zones were delineated for each municipal production well, the first zone is 50 days time of travel (TOT), the second zone is 2 years TOT and the third zone is 5 years TOT. Different values of the radius of WHPA of each well were obtained using the three methods. Consequently, several industrial installations were laid inside the WHPA according to the radius values. The results show that CFR method is the weakest method because it does not take into account regional groundwater flow, causing a hydraulic gradient. WHPAs identified by these methods may be either too large or too small, resulting in wellhead overprotection or under protection. Analytical Method incorporates hydrogeologic characteristics of the aquifer, groundwater flow, and hydrogeologic boundaries into the model. Often produces a WHPA that is smaller than the one produced using CRF. WhAEM2000 method is the best method because it uses a hydrogeological computer model of groundwater flow and it provides a more accurate delineation of the WHPA. It often produces a smaller area to manage than other methods. The study concluded that all industrial installations located in the WHPA should be carefully checked and investigated by governmental authorities. Mitigation measures for pollutants and licenses for the establishment of any new industrial installations could be based on the delineation of WHPAs using the previously mentioned methods.
\end{abstract}

Keywords: Groundwater Well, Protection Plan, Travel Time, Pollution

\section{Introduction}

Many efforts are introduced in local and regional scales to protect the valuable groundwater recourses. One method of groundwater protection is to minimize the potential of groundwater contamination is to protect a portion of the land area supplying water to the well as a wellhead protection area (WHPA). The US Environmental Protection Agency (U.S. EPA) defined a wellhead protection area as the "surface or subsurface area surrounding a water well or wellfield supplying a public water system, through which contaminants are reasonably likely to move toward and reach such well or well- field" [1]. Delineation of the wellhead protection area is the process of determining what geographic area should be included in a wellhead protection program. This area of land is then managed to minimize the potential of groundwater contamination by human activities that occur on the land surface or in the subsurface.

This paper studied the delineation of wellhead protection areas for the municipal supply wells in Gaza Governorate because there is no study that covers the protection of municipal wells from potential sources of pollutions by considering the Groundwater Protection Regulation (GWPR) developed by Palestinian Water Authority (PWA). The study illustrated the level of influence of all 
potential sources of pollutions about municipal wells.

The main aim of this article was to provide specifications and guidelines that can be used for groundwater pollution control regulations which can be part of PWA water regulations and delineation of Wellhead Protection (WHP) plans in Gaza Governorate. WHPA must be delineated separately for each municipal well and well-field to which the requirement to delineate this area applies. The WHPA represents a surface projection of the entire 3-dimensional capture area from which the water that is pumped from the well or well-field originates. Each WHPA should be sub-divided into well capture zones to distinguish among the areas of different potential risks posed to well water quality from various types of microbiological and chemical contaminants that could enter the water table and/or move with the groundwater flow to the well, and to facilitate effective and economical management of those risks. This variation in the risk potential throughout the WHPA results from the fact that bacteria have a limited life span and an adequate travel time from the point of entrance to the well may effectively inactivate these organisms. Similarly, over time, some chemical contaminants degrade into lower risk compounds or are absorbed by the geological materials encountered along the flow path. On the other hand, other chemicals are stable in a groundwater setting and the risk from their presence may only be attenuated through dilution along the flow path.

The current research used three methods for determining wellhead zoning areas. The activities and use of substances that are potential sources of pollutions in the wellhead protection zones were also identified.

Microbiological groundwater protection zone are established on the basis that the vast majority of pathogenic bacteria die off within 50 days of being in groundwater under normal conditions. Thus by establishing the distance traveled by groundwater in 50 days for a particular area, a zone can be defined from the abstraction point.

The definition of zones for chemical protection has also been attempted but this has been far less successful than the delineation of microbiological zones. This is because, unlike microbiological survival rates, it has proved extremely difficult to establish or even estimate the half-life of many chemicals in groundwater. Not only is there a vast number of chemical compounds which may be found in water, but groundwater and aquifers (particularly hard rock aquifers) frequently have a complicated chemistry themselves which may interact with pollutants and extend or reduce half-life. A 400-day isochron has been suggested in some quarters as being sufficient, but in reality far more work is needed in this area and chemical persistence will vary with different chemicals and aquifers [1].

A WHPA can be delineated utilizing several different standards or criteria. Five criteria that may form the basis of WHPA delineation are identified. Numerous methods are available to determine WHPA specifications based on chosen criteria. The criteria are: distance, drawdown, time-of-travel (TOT), flow boundaries, assimilative capacity (its capacity to receive waste waters or toxic materials without deleterious effects and without damage to aquatic life or humans who consume the water). The distance criterions delineate the WHPA by assigning a radius or other variable dimension from a pumping well. The drawdown criterion establishes the WHPA based on the magnitude of water level drawdown caused by the pumping well. Utilizing the TOT criterion, the WHPA boundary is determined based on time required for water or conservative contaminants to travel through the aquifer and reach the well. The flow boundary criterion incorporates the locations of physical or hydraulic features that control groundwater movement such as a groundwater divide or known discharge area. The assimilative capacity criterion incorporates the geologic formations capacity to dilute or attenuate contaminants to acceptable levels before they reach the supply well [2].

A WHPA based on time of travel is the area surrounding a well or well field that contributes groundwater flow to the well within a specified period of time. As example of using WHPA under Ohio's WHP Program suppliers delineate WHP areas based on a five-year time-of-travel. In other words, if drops of groundwater located at the well could backtrack to where they were located five years ago, these locations would mark the five-year time-of-travel boundary of the WHPA. The five-year time of travel criterion fulfills Ohio's WHP Program objectives by allowing a supplier time to respond to groundwater contamination reaching the WHPA. Theoretically, if a spill occurs just outside the controlled zone and results in groundwater contamination, a supplier still has five years to try to control or remove the plume, put in a treatment system, or develop an alternate supply before the contaminants reach the pumping well. The five-year time-of-travel area also provides a manageable area on which suppliers can focus their pollution prevention activities [2].

There were various types of groundwater protection measures which were used in different part of the world. Each measure had its strength and weaknesses. Consequently, there was not one measure which can be universally adopted to protect Australia's groundwater. Each State and Territory will need to examine the range of, measures available and adapt one or more of these measures to their particular circumstances and local needs. The choice of suitable measures will not only depend on the physical properties of the groundwater body and the nature and type of contamination, but also can legislative, financial, social, environmental, and political considerations. This legislation can be grouped under three broad headings:

- Groundwater Management. 
- Land-use Planning.

- Environment Protection [3].

The steps in developing Wellhead Protection Plan in the Burlington City in United States are: Phase I defines the area to be protected and managed for wellhead protection. This is the subsurface area surrounding a well that supplies a public water system, through which contaminants are likely to move through and reach the well. The boundaries are scientifically calculated. Phase II is to create a contaminant source inventory with the purpose to identify potential sources of contamination which may impact the public water supply well. Phase III of the plan is through zoning and land use management. The City will incorporate essential elements of its wellhead protection plan into its zoning ordinances and land use planning. Residents and businesses within the wellhead protection area will be notified by mail and informed of the importance of preventing the release of pollutants within the areas [4].

A comprehensive and effective legislative framework is essential for the smooth operation of the water sector and for it to meet its goal of providing an adequate water supply (Figure 1). The key principle that should underlie the legislative structure of the drinking-water sector should be to protect and improve public health through the sustainable provision of drinking-water of adequate quality in sufficient quantities to all the population continually at a price which is affordable. Legislation should be flexible and dynamic and respond to developments with-in the sector rapidly and coherently.

The legislation will empower the surveillance bodies, both financial and health-based, to closely monitor the water supplier to ensure that they met statutory functions which guarantee the supply of wholesome drinking-water [5].

Regulation is sets of commands issued by governments, which are designed to control behavior, with accompanying 'police forces' and penalties that it aims to improve access to services, ensure the quality of service and promote efficiency in the production and consumption of services, in addition to protection of the customer.

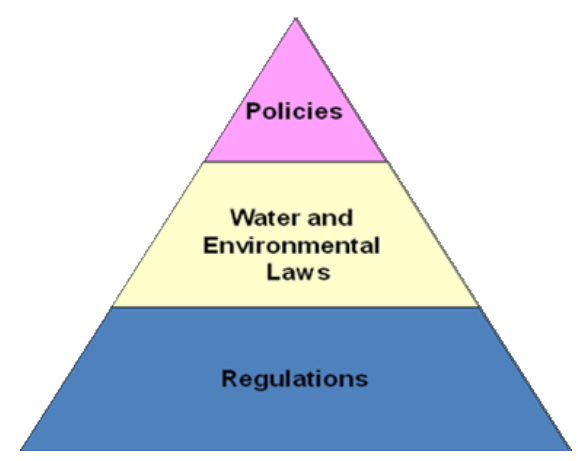

Figure 1. Legislation framework.

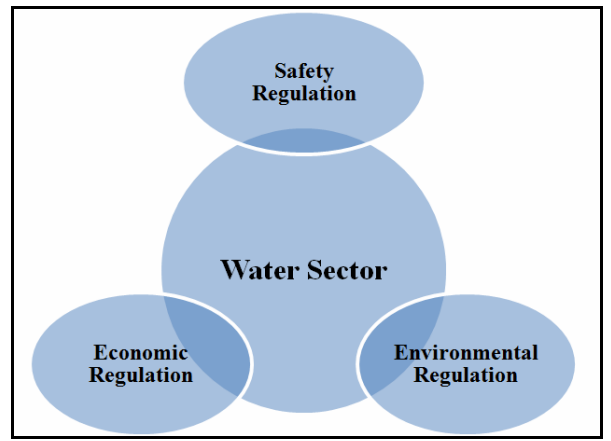

Figure 2. PWA regulations.

It deals primarily with issues related to the cost and quality of services, as they are perceived by the individual consumer. The regulation should apply equally to all water service providers regardless of whether they are private or public sector entities [6].

Regulation plays a critical role in influencing the performance of utility industries, and hence the quality and coverage of services available to citizens. The PWA has recently developed some regulations as an output of water laws. These regulations are: Safety Regulation, Environmental Regulation, and Economic Regulation (Figure 2). This research focuses on Wellhead protection area which is an important part of PWA regulations (Environmental Regulations) and it will help PWA and Environment Quality Authority (EQA) to grant license for environmental sound land use.

\section{Methods of Determining the Zoning Dimension}

Three classes of methods to delineate WHPA boundaries were identified in this article. These methods varied considerably in input data requirements, difficulty of application and cost. The classes were as follow:

- Calculated fixed-radius circles (CFR)

- Analytical methods

- Wellhead Analytic Element Model (WhAEM2000)

\subsection{Calculated Fixed-Radius Method (CFR)}

Calculated Fixed Radius method also known as the "cylinder method", is easy to use and is based on simple hydrogeological principles that require limited technical expertise. However, this method tended to overprotect down-gradient and under protect up-gradient areas because it did not account for regional gradients. Calculated fixed radius capture zones were circular areas whose radius was determined using Equation 1 [7]:

$$
r=\sqrt[2]{\frac{Q t}{\pi b n}}
$$


where:

$\mathbf{r}=$ radius (distance from well) in meters

$\mathbf{Q}=$ maximum approved pumping rate of the well $\left(\mathrm{m}^{3} /\right.$ day $)$

$\mathbf{t}=$ saturated travel times for each well capture zone (50 days, 2 years, 5 years)

b =saturated thickness of screened interval

$\mathbf{n}=$ porosity

$\boldsymbol{\pi}=3.14156 \ldots$

\subsection{Analytical Method}

Equation 2 was used to compute the time of travel in $\mathrm{x}$ axes.

$$
\mathrm{t}_{\mathrm{x}}=\frac{\mathrm{n}}{\mathrm{ki}}\left[\mathrm{r}_{\mathrm{x}}-\left(\frac{\mathrm{Q}}{2 \pi \mathrm{kbi}}\right) \ln \left\{1+\left(\frac{2 \pi \mathrm{kbi}}{\mathrm{Q}}\right) \cdot \mathrm{r}_{\mathrm{x}}\right\}\right]
$$

$\mathrm{t}_{\mathrm{x}}=$ time of travel (days)

$\mathrm{n}=$ effective porosity (fraction)

$\mathrm{K}=$ hydraulic conductivity (meters per day)

$r_{x}=$ distance over which groundwater travels in $t_{x}$ before entering a pumping well $(\mathrm{m})$, being negative $(-)$ if down gradient and positive $(+)$ if up gradient

$\mathrm{Q}=$ pumping rate from the well (cubic meters per day)

$\mathrm{b}=$ aquifer thickness (meters)

$\mathrm{i}=$ hydraulic gradient before pumping

Equations 3, 4 and 5 developed by using Taylor-series besides developing a computer program (Modflow) for the new method aiming at the delineation of groundwater wellheads protection: upstream, downstream, and perpendicular to the flow lines [7].

For the up gradient protection distance, Equation 3 was used to compute the maximum gradient protection distance $\left(\mathrm{r}_{\max }\right)$.

$$
\begin{gathered}
\mathrm{r}_{\max }(\mathrm{m})=\left(0.00002 \gamma^{5}-0.0009 \gamma^{4}+0.015 \gamma^{3}\right. \\
\left.+0.37 \gamma^{2}+\gamma\right) / \mathrm{F}
\end{gathered}
$$

With $\gamma=2 K i \sqrt[2]{\frac{\pi \cdot b \cdot t}{Q . n}}$ (dimensionless) and

$$
F=\frac{2 \pi K b i}{Q} \quad\left(\mathrm{~m}^{-1}\right)
$$

For the down gradient protection distance, the minimum distance $\left(\mathrm{r}_{\min }\right)$ was calculated by using Equation 4 .

$$
r_{\min }(m)=\left(0.042 \gamma^{3}+0.37 \gamma^{2}+1.04 \gamma\right) / F
$$

For the protection distance perpendicular to the direction of flow $\left(r_{p}\right)$, Equation 5 was used as follows:

$$
\mathrm{r}_{\mathrm{p}}=\sqrt[2]{\frac{Q t}{\pi b n}} \quad(\mathrm{~m})
$$

There are number of limitation to the application of this method. These limitations can be classified as fol- lows:

- For computing up gradient protection distance $\left(\mathrm{r}_{\max }\right)$, combinations of input parameters resulting in a value of $\gamma>18$, should not be used this method. Visual Modflow models were run with combinations of input parameters that give a maximum value of $\gamma$ up to 18 . Values of $r_{\max }$ for $\gamma$ larger than 18 are not found.

- For computing down gradient protection distance $\left(\mathrm{r}_{\min }\right)$, a minimum protection distance of $25 \mathrm{~m}$, should be applied if $\gamma<-3.5$ because the values of $r_{\min }$ become very small. In addition, Equation 4 should be not applied with values of effective porosity smaller than $0.1(10 \%)$.

- For computing protection distance perpendicular $\left(r_{p}\right)$ to the direction of flow; and If $r_{\max }$ is more than four times rmin, the possible calculation error can be more than $15 \%$. Since this only leads to overprotection, it should not be a serious limitation. An error of $15 \%$ probably is irrelevant concerning the uncertainty of the input data.

\subsection{Wellhead Analytic Element Model (WhAEM2000)}

The U.S. Environmental Protection agency EPA's Wellhead Analytic Element Model, WhAEM2000 is a computer tool to support step-wise, progressive modeling, and delineation of source water areas for pumping wells. Each solution was conceptually more sophisticated, and it is assumed that the corresponding calculated capture zones were progressively more realistic. The emphasis of the WhAEM2000 project on "ease-of-use" and computational efficiency does not release the modeler, from responsibilities in justifying the conceptual models, and defending the reasonableness of the solutions. The uncertainties were emphasized in conceptualization of the boundary conditions in this study, but uncertainties in parameterization are also important [8].

The calculations of WHPA dimensions using WhAEM 2000 depend on several parameters, including the magnitude and direction of the ambient flow near the well or well field, which is challenging to characterize. The magnitude of the uniform flow was denoted by Qo $\left(\mathrm{m}^{2} /\right.$ day $)$, and estimated from the hydraulic gradient i [-] and the aquifer transmissivity $\mathrm{kH}$ (hydraulic conductivity $\mathrm{k}$ times saturated aquifer thickness $\mathrm{H})\left(\mathrm{m}^{2} /\right.$ day) [9]. The magnitude of the uniform flow rate was calculated as:

$$
\mathrm{Q}_{\mathrm{o}}=\mathrm{kHi}
$$

The flow $Q_{0}$ is the total amount of water in the aquifer integrated over the saturated thickness, per unit width of the aquifer. The shape and size of a simplified timeof-travel capture zone can be related to a dimensionless travel time parameter, $\breve{T}$, defined as

$$
\stackrel{\vee}{\mathrm{T}}=\frac{\mathrm{T}}{\mathrm{T}_{0}}
$$


where $\mathrm{T}$ is the time-of-travel and $\mathrm{T}_{0}$ is a reference time defined as:

$$
T_{0}=\frac{n H Q}{2 \pi Q_{0}^{2}}
$$

where $\mathrm{n}$ is the aquifer porosity [-], and Q $\left(\mathrm{m}^{3} /\right.$ day) is the pumping rate of the well.

When $\breve{T} \leq 0.1$, the radius (R) centered on the well, including a safety factor for a non-zero ambient flow field, is given by

$$
R=1.1543 \sqrt{\frac{(Q T)}{(\pi H n)}}
$$

When $0.1<\overleftarrow{\mathrm{T}} \leq 1$, the $\mathrm{R}$ is given by

$$
R=L_{s}[1.161+\ln (0.39+\stackrel{v}{T})]
$$

where $L_{s}$ is the distance from the well to the stagnation point down gradient from the well given by

$$
L_{s}=\frac{Q}{2 \pi Q_{0}}
$$

and where the eccentricity $\delta$ is the measure of the deviation from center of circular to center of well given by

$$
\delta=L_{s}[0.00278+0.652 \stackrel{\mathrm{T}}{\mathrm{T}}]
$$

When $\check{\mathrm{T}}>1$, a uniform flow envelope, the so-called boat-shaped capture zone, can be defined as

$$
X=y / \tan \left(y / L_{s}\right)
$$

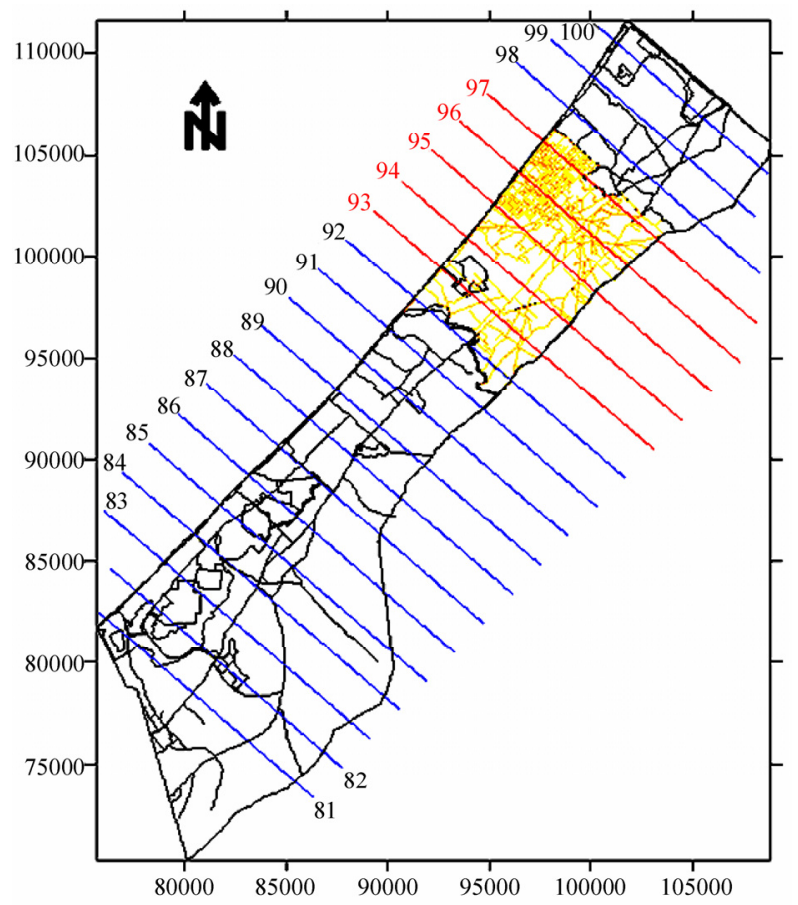

where y is bounded by

$$
-\frac{Q}{2 Q_{0}}<y<+\frac{Q}{2 Q_{0}}
$$

and clipped at the up-gradient distance Lu given by

$$
L_{u}=L_{s}[\stackrel{v}{\mathrm{~T}}+\ln (\mathrm{e}+\stackrel{v}{\mathrm{~T}})]
$$

and where $(\mathrm{e}=2.718)[9]$.

\section{Study Area}

\subsection{Aquifer Data}

Classification of the lithological cross sections of the aquifer of the municipal wells for is very essential to apply Analytical method. Among of 20 sections, five sections were located in Gaza Governorate as shown as Figure 3. These cross sections show the distribution of impervious to semi-impervious layers and lenses alternating with predominantly permeable sand and calcareous sandstones. These sections represent the upper part of Kurkar Group (costal aquifer) since the depths of the available wells are limited. Clay layers divide the aquifer vertically into four sub-aquifers as mentioned before $\mathrm{A}$, $\mathrm{B} 1, \mathrm{~B} 2$ and $\mathrm{C}$. The upper sub-aquifer " $\mathrm{A}$ " is unconfined, whereas sub-aquifers " $\mathrm{B} 1, \mathrm{~B} 2$, and $\mathrm{C}$ " become increasingly confined towards the sea. These sections helped to know depth of aquifer for each well.
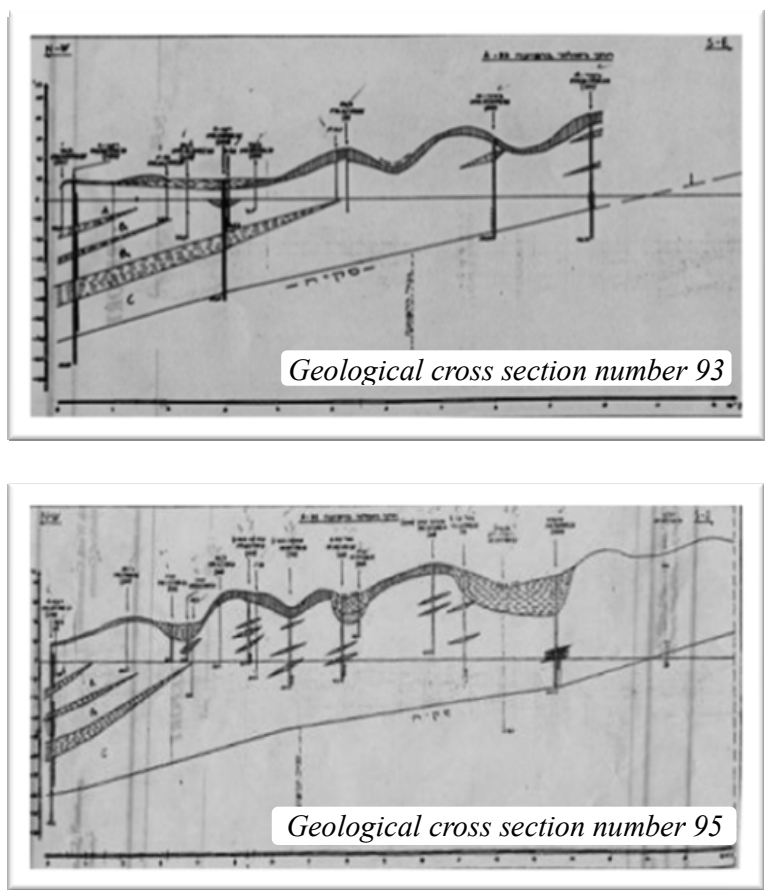

Figure 3. Cross sections for Gaza Strip Aquifer [10]. 


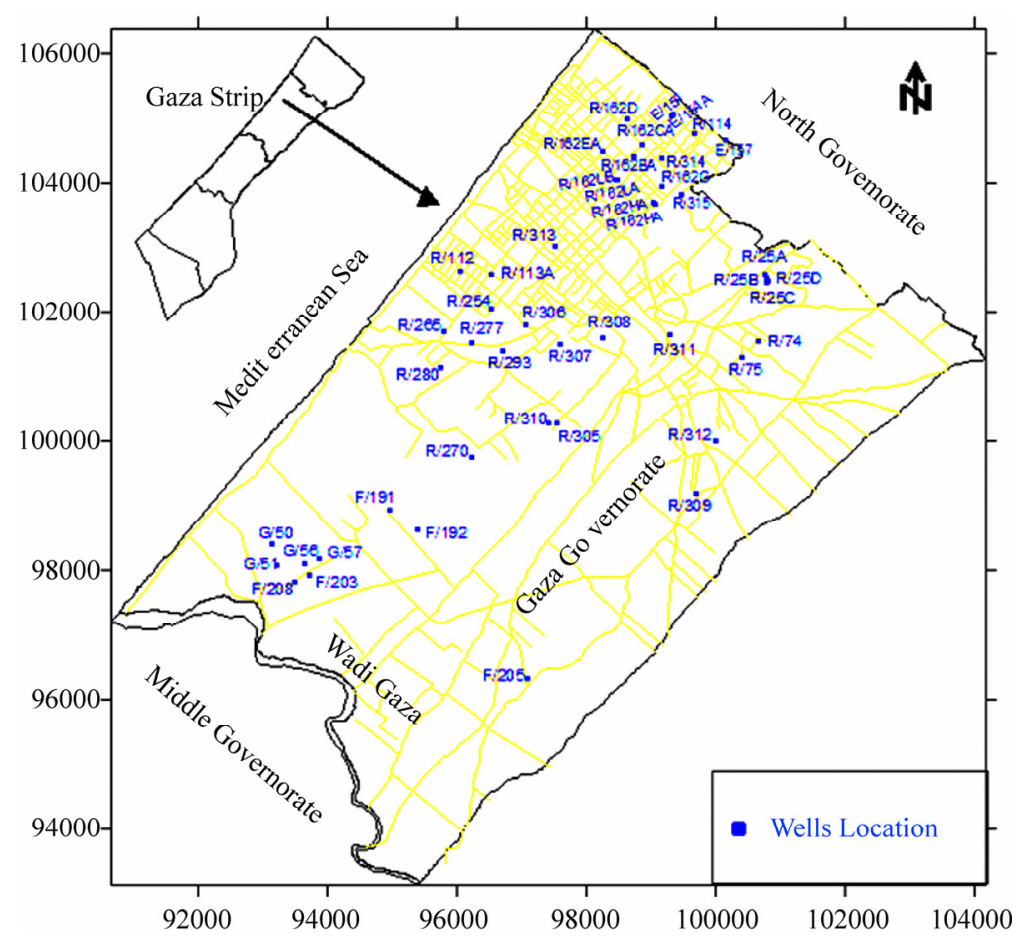

Figure 4. Location map of drinking water wells in the study area [11].

The presence of clay with silty clay, sandy clay and sandy silty clay on the surface will retard the movement of contaminate to travel very slowly until reach to groundwater. The section number of aquifer was identified for each well, according to the nearest section of the well and with identification of the distance far from the sea and determination the total depth for each well, and then measured the depth of aquifer which helps account WHPA.

The aquifer depth was computed by selecting the section number, far from sea and the total depth. After that the sections from Figure 3 were used to determine the aquifer depth. It can be seen that the range of aquifer depth is between $32 \mathrm{~m}$ and $150 \mathrm{~m}$ when the average of aquifer depth is $77 \mathrm{~m}$.

The hydraulic gradient (i) was computed by using Equation 15:

$$
\mathrm{i}=\frac{\Delta \mathrm{h}}{\mathrm{F}} \frac{(\mathrm{Z}-\mathrm{DTW})}{\mathrm{F}}
$$

i $\quad=$ Hydraulic Gradient

DTW =depth to water

$\Delta \mathbf{h} \quad=$ deference between $\mathrm{Z}$ coordinate and DTW

F $\quad=$ far from sea

The maximum of hydraulic gradient was 0.0028 where the average value of the hydraulic gradient was 0.0008 .

\subsection{Drinking Water Wells Data}

The data concerned with drinking water wells that lie within the Gaza Governorate and the number of existing drinking wells is 47 wells as shown in Figure 4. The data include the name and coordinates and the number of operating hours to each well, mean value of abstraction, sections of groundwater, water level, porosity, and permeability. These data were used in the delineation of WHPA by the three methods.

\subsection{Pollution Activities Data}

The Pollutants were identified and the extent of the danger to the environment and groundwater due to industrial activities were selected in industrial installations manual 2005. This manual was adopted by the Environmental Quality Authority (EQA) and the activities are divided into three categories according to the dangerous of each industrial installation as follow:

- A category (A): a group of industries of less dangerous waste on human health and the environment such as Paper and Carton Industry.

- A category (B): a group of industries of medium dangerous waste on human health and the environment such as Block Industry.

- A category (C): a group of industries of high dangerous waste on human health and the environment such as Asphalt Industry.

The category $(\mathrm{C})$ industries were chosen because they produce high dangerous waste. This category consists of 157 facilities. These facilities were classified into 14 types 
and these types were divided into four groups according to article pollution. It is important to note that Gaza waste landfill and Gaza water treatment plant were added to category $\mathrm{C}$ as a group five.

Site visits were conducted to each facility. The exact positions of these facilities were located by Global Positioning System (GPS). It was found that some of the facilities have been closed due to the recent economic and political reasons. Summary of the industrial facilities that located in the study area is presented in Figure 5.

\section{Results}

CFR method was applied for all municipal wells in the study area boundaries. Figure 6 represents the zone boundary at 50 days, 2 years and 5 years TOT for each well in Gaza Governorate boundaries respectively.

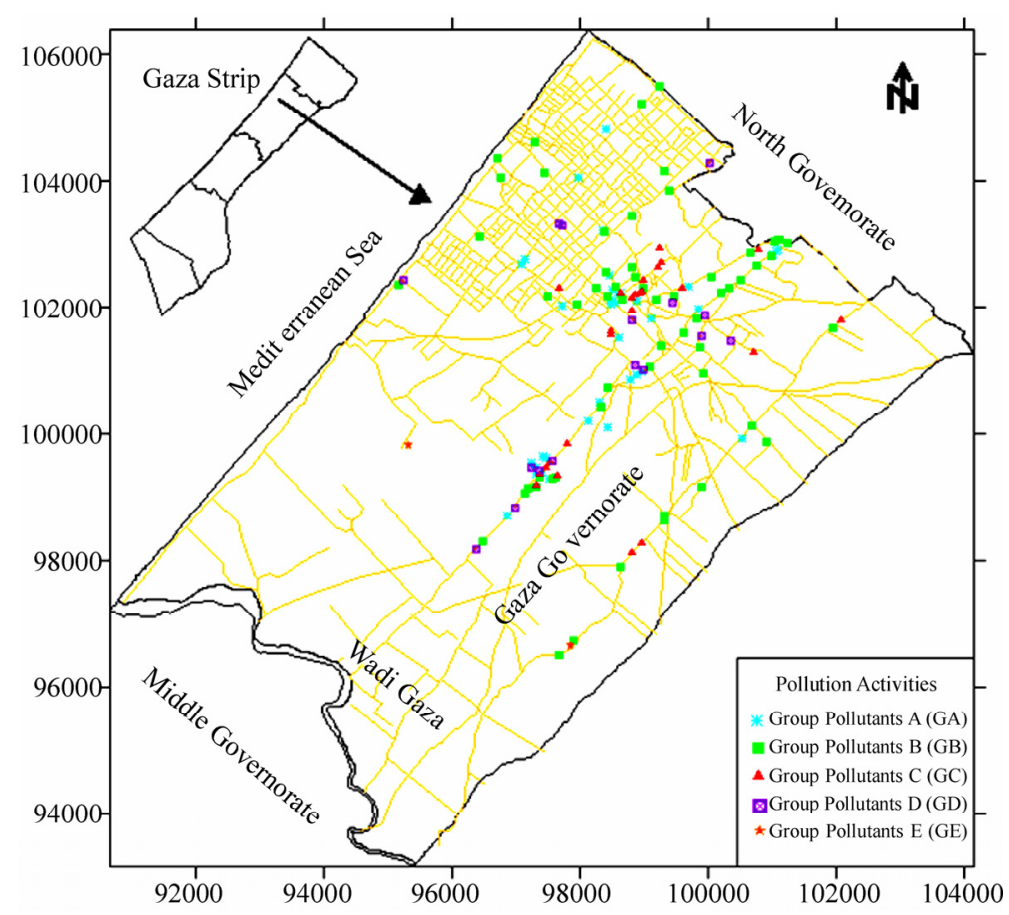

Figure 5. Location map of pollution activities in the study area.

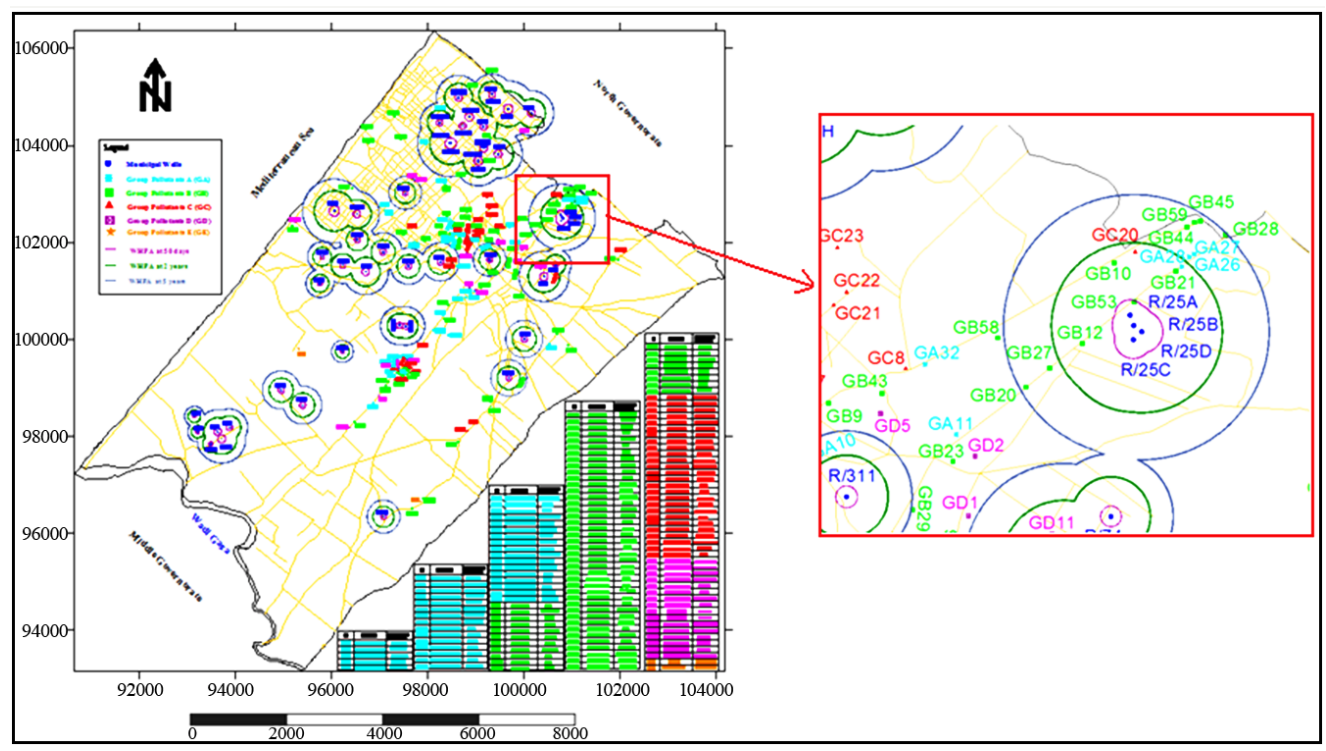

Figure 6. Calculated Fixed Radius (CFR) method for calculating WHPA at (50 days, 2 years, 5 years). 


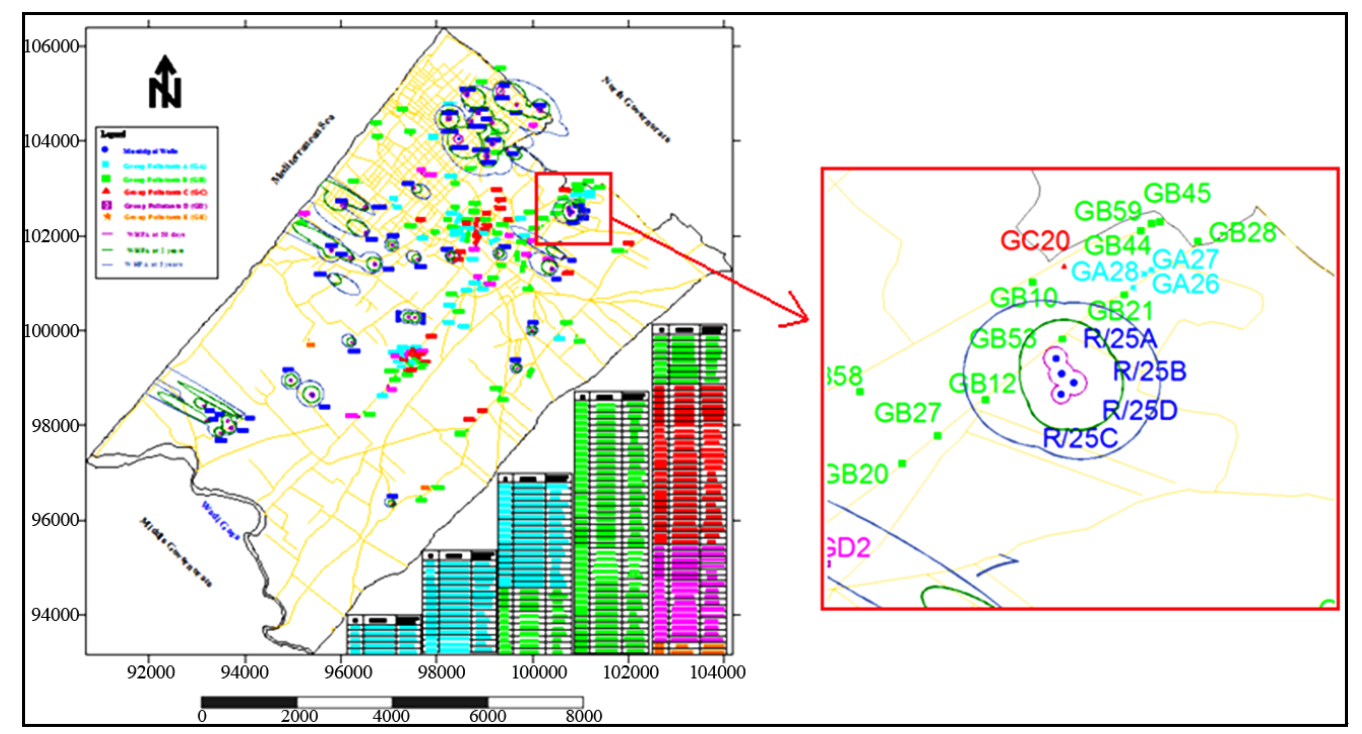

Figure 7. Analytical method for calculating WHPA at (50 days, 2 years, and 5 years).

Results showed that when CFR method was used on total 2 industrial installations lie in WHPA for 50 days TOT where the average of the radius is about $71 \mathrm{~m}, 13$ industrial installations lie in WHPA for 2 years TOT where the average of the radius is about $217 \mathrm{~m}$, and 32 industrial installations lie in WHPA for 5 years TOT where the average of the radius is about $429 \mathrm{~m}$. From the results, it can be recommended that by using CFR method any industrial installation should be prohibited in any distance less than $430 \mathrm{~m}$ from the well.

The advantages of Calculated Fixed Radius (CFR) method that it is simple, low cost, and does not require significant amount of data acquisition, however the disadvantages consist of generally not representative of the groundwater system, prone to legal challenges, tends to over protect downgradient and under protect upgradient, and often yields larger area than other methods.

The analytical method using Equations 3, 4 and 5 was applied for all municipal wells in study area boundaries. Figure 7 represents the zone boundary at 50 days, 2 years and 5 years TOT for each well in Gaza Governorate boundaries respectively.

The average of the ellipse radiuses of 50 days zone $r_{\max }, r_{\min }$, and $r_{p}$ are about $42 \mathrm{~m}, 31 \mathrm{~m}, 37 \mathrm{~m}$ respectively, for 2 years are about $328 \mathrm{~m}, 91 \mathrm{~m}$, and $140 \mathrm{~m}$ respectively and for 5 years are about $862 \mathrm{~m}, 149 \mathrm{~m}$, and $222 \mathrm{~m}$ respectively. From these results, it can be recommended that by using analytical method any industrial insulation should be prohibited in any ellipse radiuses $r_{\max }, r_{\min }$, and $r_{p}$ less than $862 \mathrm{~m}, 150 \mathrm{~m}$, and $223 \mathrm{~m}$ respectively around the well.

Analytical Method showed that are no industrial installations lie in WHPA for 50 days TOT, 2 industrial installations lie in WHPA for 2 years TOT, and 10 industrial installations lie in WHPA for 5 years TOT. From the results, it can be recommended that by using analytical method, any industrial installation should be prohibited in any ellipse radiuses $r_{\max }, r_{\min }$, and $r_{p}$ less than 862 $\mathrm{m}, 150 \mathrm{~m}$, and $223 \mathrm{~m}$ respectively around the well.

The advantages of Analytical Method are incorporates hydrogeologic characteristics of the aquifer, groundwater flow and hydrogeologic boundaries into the model, provide for a defensible delineation of the WHPA, and are based on site-specific information. Often produces a WHPA that is smaller than the one produced using CFR however the disadvantages consist of assumes a uniform aquifer (note that some exceptions to this do exist), requires significant expertise, and is moderately costly.

The WhAEM2000 method using Equations 6-14 was applied for all municipal wells in the study area boundaries. Figure 8 represents the zone boundary at 50 days, 2 years and 5 years TOT for each well in Gaza Governorate boundaries respectively.

The average of the travel time parameter $(\breve{T})$ of 50 days is 0.0626 (dimensionless), $81 \%$ from values $\breve{T}$ is less than 0.1 and the average of radius (R) is about $43 \mathrm{~m}$, $19 \%$ between $(0.1<\breve{\mathrm{T}}<1)$ and the average of radius $(\mathrm{R})$ and the average of eccentricity $(\delta)$ is about $36 \mathrm{~m}, 7 \mathrm{~m}$ respectively and no value of $\breve{\mathrm{T}}$ more than 1 . For 2 year $(\breve{\mathrm{T}})$ is $0.9065,34 \%$ from $\breve{T}$ values is less than 0.1 and the average of radius (R) is about $156 \mathrm{~m}, 34 \%$ between $(0.1<\overleftarrow{\mathrm{T}}<1)$ and the average of radius $(\mathrm{R})$ and the average of eccentricity $(\delta)$ is about $136 \mathrm{~m}, 32 \mathrm{~m}$ respectively and $32 \%$ from $\breve{T}$ values is more than 1 and the average boat shaped radiuses $\mathrm{L}_{\mathrm{u}}, \mathrm{L}_{\mathrm{s}}$ and $\mathrm{Y}_{\max }$ are about $276 \mathrm{~m}, 79 \mathrm{~m}$, $250 \mathrm{~m}$ respectively. For 5 year ( $\breve{T})$ is $2.2664,23 \%$ from $\breve{\mathrm{T}}$ values is less than 0.1 and the average of radius (R) is about $242 \mathrm{~m}, 32 \%$ between $(0.1<\check{\mathrm{T}}<1)$ and the average of radius $(\mathrm{R})$ and the average of eccentricity $(\delta)$ is about $254 \mathrm{~m}, 69 \mathrm{~m}$ respectively and $45 \%$ from $\breve{\mathrm{T}}$ values is more than 1 and the average $L_{u}, L_{s}$ and $Y_{\max }$ are $454 \mathrm{~m}, 79 \mathrm{~m}$, 
$250 \mathrm{~m}$ respectively.

Wellhead Analytic Element Model revealed that there are no industrial installations lie in WHPA for 50 days TOT, 3 industrial installations lie in WHPA for 2 years TOT, and 5 industrial installations lie in WHPA for 5 years TOT. From the results, it can be recommended that by using WhAEM2000 method any industrial installation should be prohibited in any boat shaped radiuses $\mathrm{L}_{\mathrm{u}}, \mathrm{L}_{\mathrm{s}}$ and $\mathrm{Y}_{\max }$ are $454 \mathrm{~m}, 79 \mathrm{~m}, 250 \mathrm{~m}$ respectively around the well.

The advantages of WhAEM2000 method are the geo- hydrology computer model of groundwater flow, provides a more accurate delineation of the WHPA. The method accounts for variation in hydraulic parameters and boundary conditions. It often produces a smaller area to manage than other methods. However, the disadvantages consist of costly relative to other methods, requires significant amount of data collection and high level of expertise to set up the grid of the model. Figure 9 represent the difference between three methods at 5 years TOT.

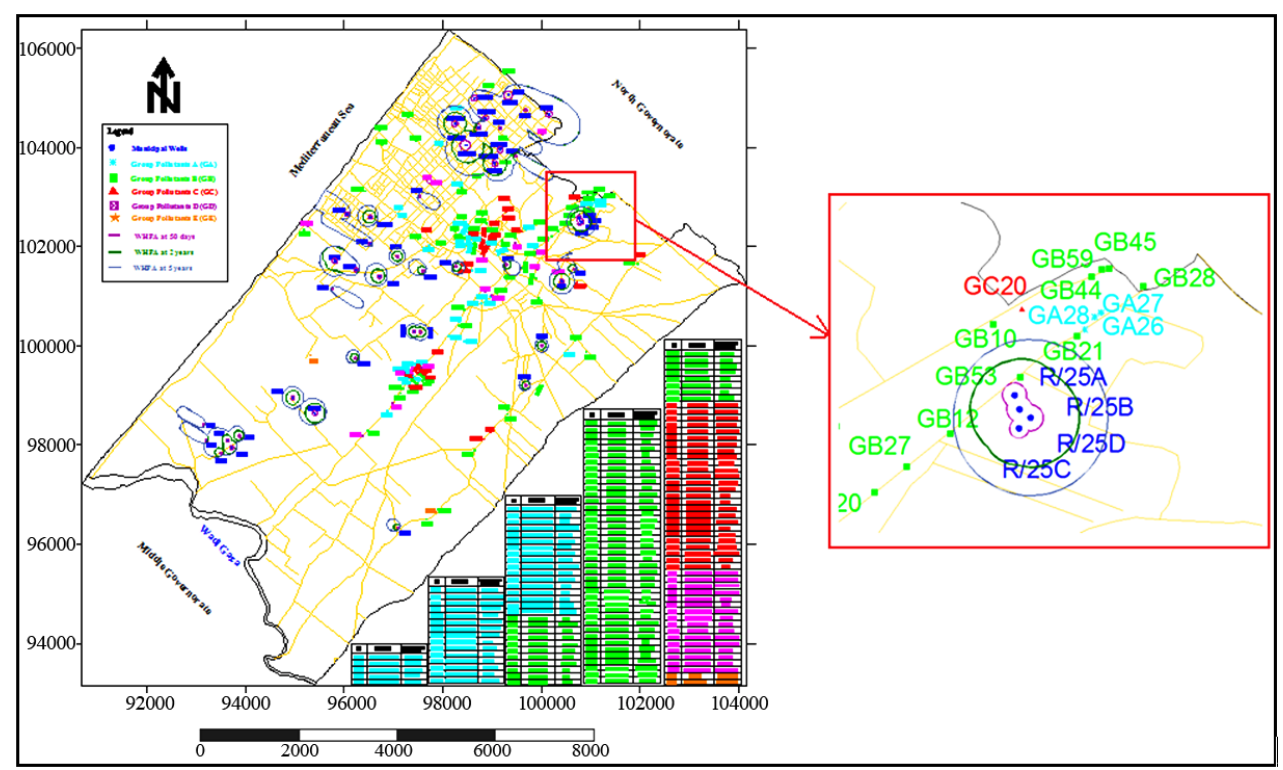

Figure 8. Wellhead Analytic Element Model (WhAEM2000) for calculating WHPA at (50 days, 2 years, and 5 years).

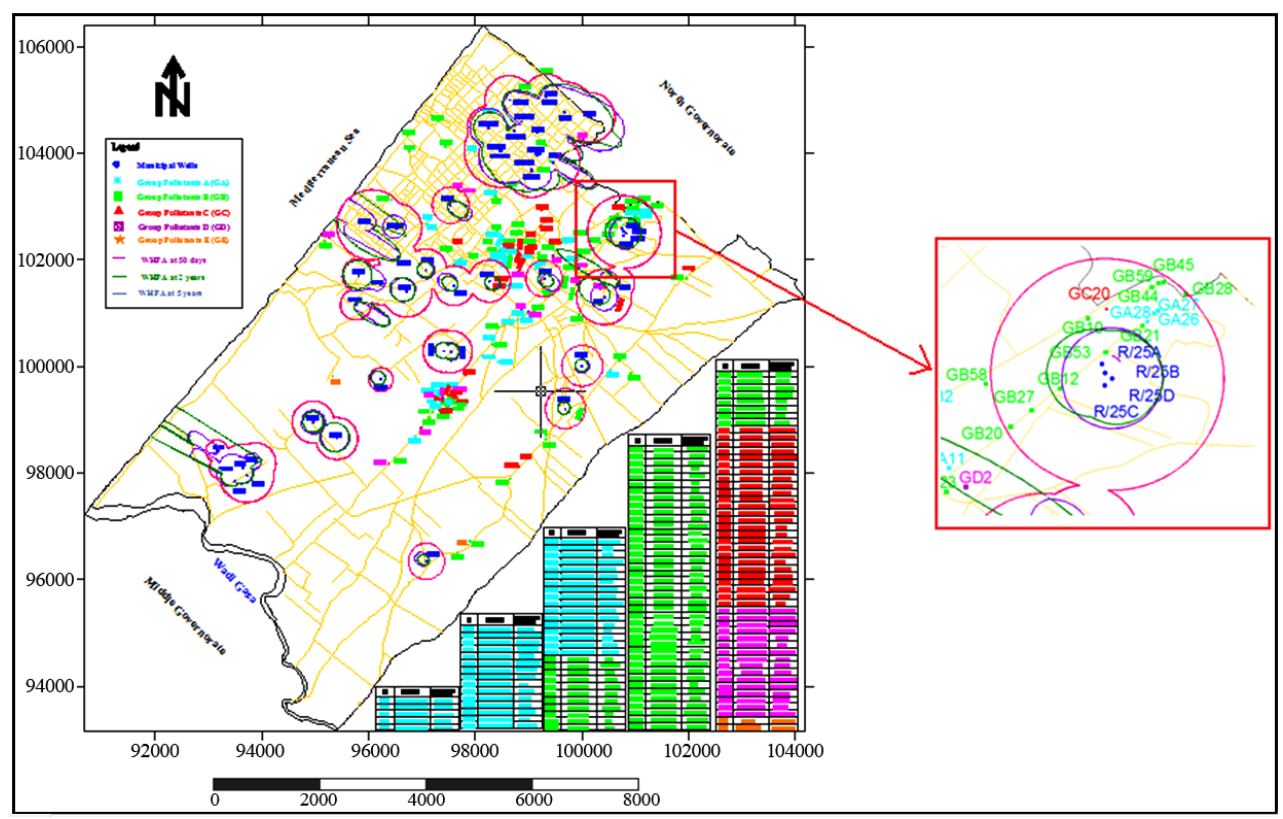

Figure 9. Difference between the three methods for calculating WHPA at 5 years. 


\section{Conclusions}

From this article it can be concluded that the three methods for delineation WHPA were successfully applied in the case of Gaza Governorate which required grated efforts to collect, screen, and analysis huge number of data (hydrogeology and industrial installations). WhAEM 2000 method was the best method because it considered the geohydrology computer model of groundwater flow and it provided accurate delineation of the WHPA. It produced a smaller area to manage than other methods. It was found that CFR method was the weakest method because it did not take into account regional groundwater flow and the influence of the hydraulic gradient. WHPAs identified by CFR method may be either too large or too small, resulting in wellhead overprotection or under protection.

The rapid rate of population growth in the Gaza Strip and dependence upon groundwater as a single water source present a serious challenge for future political stability and economic development. Therefore, hard effort should be applied to prevent the increase of deterioration of water quality in the area. Accordingly, the tested methods and the produced WHPA maps by the current research are recommended to be used by Palestinian Water Authority for licensing the new wells and by Environment Quality Authority for giving the licenses to any new industrial installations in Gaza Governorate. The current research will be further tackled using by modeling approach.

\section{References}

[1] United States Environmental Protection Agency Publications (U.S. EPA), "Guidelines for delineation of wellhead protection areas," Office of Groundwater Protection, Washington, 1987.

[2] J. Bates and J. Evans, "Evaluation of wellhead protection area delineation methods, applied to the Municipal Well Field at Elmore," Ottawa County, Ohio, 1996.

[3] Management Council of Australia and New Zealand (MCOA), "Guidelines for groundwater protection in Australia, national water quality management strategy," Australia, and New Zealand, 1995.

[4] C. Wilson, "Wellhead protection overlay district," Burlington, USA, 2007. http://www.burlington-wi.gov/Spotlight/spotlight200705.htm.

[5] V. Novonty and H. Olem, "Water quality prevention, identification, and management of diffuse pollution," Van Nostrand Reinhold, New York, 1994.

[6] N. Ghbn, "Palestinian water authority, Gaza: Water resources and management master program, utility regulating and governing," Palestinian Water Authority, Gaza, 2003.

[7] B. Krijgsman and H. Ferreira, "A methodology for delineating wellhead protection areas," Lisbon, Portugal, 2001.

[8] Drinking Water and Groundwater Bureau (DWGB) (2007), "Delineating wellhead protection areas," http:// www.des.state.nh.us/dwg.htm.

[9] S. Kraemer, H. Haitjema, and V. Kelson, "Working with WhAEM2000, capture zone delineation for a city wellfield in a valley fill glacial outwash aquifer supporting wellhead protection," Office of Research and Development, U.S. Environmental Protection Agency, Washington, 2007.

[10] Palestinian Water Authority (PWA), "Water resources management program," Palestine, 1991.

[11] Palestinian Water Authority (PWA), "Data records," Palestine, 2008. 